\title{
Marine Aerosols Measurements by the Tara Pacific Expedition
}

\author{
Adapted from "Tara Pacific Expedition's \\ Atmospheric Measurements of \\ Marine Aerosols across the Atlantic \\ and Pacific Oceans: Overview and \\ Preliminary Results," by J. M. Flores \\ (Weizmann Institute of Science), \\ G. Bourdin, O. Altaratz, M. Trainic, \\ N. Lang-Yona, E. Dzimban, S. Steinau, \\ F. Tettich, S. Planes, D. Allemand, \\ S. Agostini, B. Banaigs, E. Boissin, \\ E. Boss, E. Douville, D. Forcioli, P. Furla, \\ P. E. Galand, M. Sullivan, É. Gilson, \\ F. Lombard, C. Moulin, S. Pesant, \\ J. Poulain, S. Reynaud, S. Romac, \\ S. Sunagawa, O. P. Thomas, R. Troublé, \\ C. de Vargas, R. Vega Thurber, \\ C. R. Voolstra, P. Wincker, D. Zoccola, \\ C. Bowler, G. Gorsky, Y. Rudich, A. Vardi, \\ and I. Koren. Published online in BAMS, \\ May 2020. For the full, citable article, see \\ DOI:10.1175/BAMS-D-18-0224.1.
}

A erosols in the marine atmospheric boundary layer are significant in the global radiative budget. As such, there is a critical need to understand how these aerosols are produced and behave in-and interact with-the atmosphere and ocean.

The main component (by mass) of marine aerosol, sea spray aerosol (SSA), also plays a major role in aerosol-cloud interactions determining the initial size distribution and number concentration of drops in marine clouds. A secondary source is through oxidation products of volatile organic compounds, such as dimethylsulphide.

SSA production fluxes and their dependence on oceanic and atmospheric conditions are still greatly uncertain. Current estimates of global SSA mass in the atmosphere range between 0.02 and $1 \times 1014 \mathrm{~kg} \mathrm{yr}^{-1}$. Rough estimates of the radiative cooling effect of SSAs range from $0.08-6 \mathrm{~W} \mathrm{~m}^{-2}$, and their contribution to total aerosol optical depth is estimated to range between $18 \%$ and $50 \%$. Unlike optical depth and mass concentration, estimates of the emitted SSA size distribution can be constrained only by in situ measurements.

Transport of aerosols from the continents to the marine environment (including pollution, pollen, mineral dust, etc.) is also a major source of marine aerosol. Mineral dust in particular can be transported for thousands of kilometers and makes up a significant fraction of the particulates in the marine boundary layer. Expected climate change trends (i.e., enhanced drought and desertification) are expected to result in an increase of mineral dust, but its radiative forcing is still undefined: it can heat or cool the climate, and due to the 


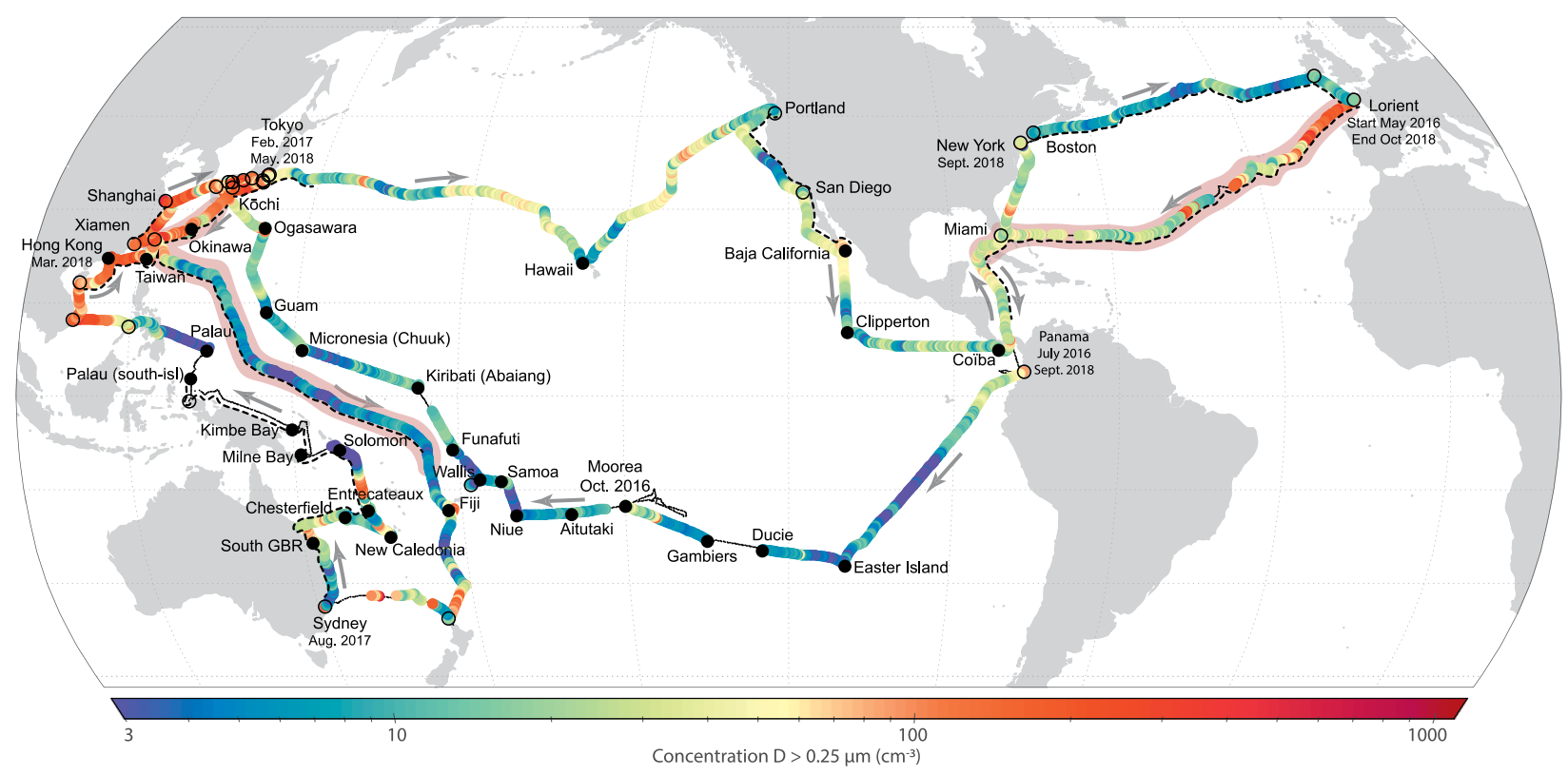

lack of sufficient data its scattering properties are not easy to determine. Additionally, mineral dust aerosols can provide particulate iron phosphate essential for blooms in the oceans.

Despite increased understanding of the effects of SSA in cloud processes, radiation balance, and atmospheric chemistry, it is still uncertain how this knowledge can be used to predict the climate. Therefore, it is necessary to characterize marine aerosol particles, and understand their formation mechanisms and their physical and chemical changes as they are transported.

We collected marine aerosol measurements in various oceanic and atmospheric conditions during the Tara Pacific Expedition along an approximately $110,000-\mathrm{km}$ route in the Atlantic and Pacific Oceans. Our preliminary results in this unprecedented scientific campaign demonstrate the comprehensive database of marine aerosol properties we are currently building.

\section{Tara Pacific Expedition 2016-18}

In May 2016, the Tara Ocean Foundation embarked on the Tara Pacific Expedition, a 2.5-yr research project aimed at understanding coral reefs and their associated surface plankton ecosystem. R.V. Tara is a 36-m-long, 10-m-wide aluminum hull schooner equipped to measure air temperature, relative humidity, and pressure, as well as water temperature and salinity (1.5 m under the waterline). The photosynthetically active radiation was measured next to the weather station, recorded continuously,
$\Delta$

* Route of the Tara Pacific Expedition 2016-18 visualized by the OPC aerosol concentration of $D>0.25 \mu \mathrm{m}$. The black line shows the full route of the expedition, but where no aerosol data were collected. The gray arrows indicate the direction Tara sailed. The black dotted line shows the areas the SMPS was working. The black full circles denote coral holobionte sampling sites, and the black open circles denote any other stopover. The expedition was mainly dedicated to coral reefs.

and averaged per minute. Atmospheric transmittance was also measured daily.

The three aerosol instruments aboard Tara were a scanning mobility particle sizer (SMPS) for size distribution measurements from 0.01 to $1.089 \mu \mathrm{m}$ an optical particle counter for (OPC) 0.25 to $32 \mu \mathrm{m}$, and a custom aerosol filter system. We also installed wide-angle time-lapse cameras to record the state of the ocean and the clouds. The Tara measurements allow us to establish a comprehensive database about marine aerosol properties and their link to ocean-atmosphere interaction and feedbacks.

\section{Marine aerosol size distributions}

We analyzed April and May 2017 in the Pacific Ocean and 35 days in May-June 2016 in the Atlantic. In the western Pacific Ocean, two distinct scenarios can be seen. During openocean sailing toward Fiji, with air masses originated from the east, average total aerosol 


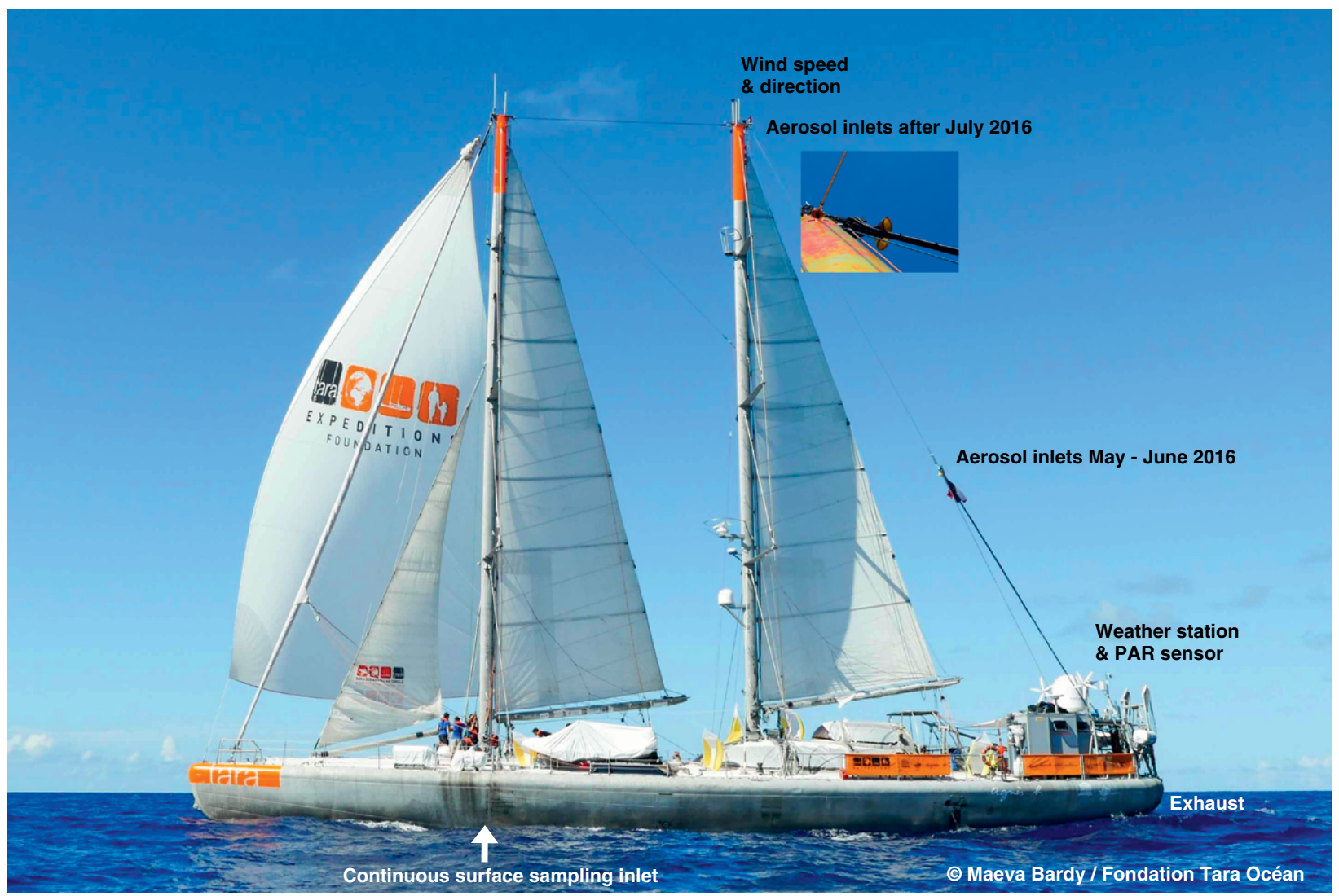

concentration was $180( \pm 51) \mathrm{cm}^{-3}$, with 83 $( \pm 30) \mathrm{cm}^{-3}$ aerosol with diameters (D) $>0.1 \mu \mathrm{m}$, which can be considered, in general, cloud condensation nuclei (CCN) for supersaturation $\geq 0.4 \%$. After a daylong rain (13-14 May) the total aerosol concentration decreased to $82 \mathrm{~cm}^{-3}$ and to $13 \mathrm{~cm}^{-3}$ for $\mathrm{D}>0.1 \mu \mathrm{m}$. The aerosol concentration after the rain can be speculated to be the background pristine concentration in the marine boundary layer.

On the other hand, during a period with stopovers in Kochi, Okinawa, and Keelung, the total aerosol concentration rarely decreased below $1,000 \mathrm{~cm}^{-3}$; the minimum observed concentration was $388 \mathrm{~cm}^{-3}$. Even with air masses spending more than $20 \mathrm{~h}$ above the ocean (up to $1,000 \mathrm{~km}$ from the coast) the aerosol concentration in the boundary layer was polluted; for example, between Okinawa and Keelung (21-23 April), the average concentration was $2,718( \pm 1,560) \mathrm{cm}^{-3}$. It took more than $650 \mathrm{~km}$ to stop seeing the continental influence in the measurements.

The Atlantic Ocean, on the other hand, consistently had more aerosols than the Pacific. Total aerosol concentrations were greater than

\begin{abstract}
* R/V Tara instrument setup for the Tara Pacific Expedition. The inlet for aerosol sampling was installed along the backstay. For the first Atlantic crossing, the inlet was installed halfway up the backstay. The main water entrance is located in the hull $1.5 \mathrm{~m}$ under the waterline; depending on ocean conditions, the water will be sampled between 0.5 and $\mathbf{3} \mathbf{m}$ under the sea surface.
\end{abstract}

$5,000 \mathrm{~cm}^{-3}$ even $1,000 \mathrm{~km}$ away from the European continent. It was only after the Azores that the concentration decreased below $1,000 \mathrm{~cm}^{-3}$. In the North Atlantic air masses, total aerosol concentration averaged $864( \pm 806) \mathrm{cm}^{-3}$. With easterly back trajectories, concentrations averaged 422 $( \pm 591) \mathrm{cm}^{-3}$, with a minimum of $136 \mathrm{~cm}^{-3}$.

The open-ocean concentrations show a greater variation in the Atlantic than in the Pacific, with more coarse-mode aerosol for the same wind speed $\left(11 \mathrm{~m} \mathrm{~s}^{-1}\right)$. In the Pacific, sea salt was predominant, whereas mineral dust aerosol with no sodium was found in the Atlantic Ocean filters. Other mineral dust particles measured in the Caribbean Sea were internally mixed with $\mathrm{NaCl}$. Additionally, the 48-h back trajectories 

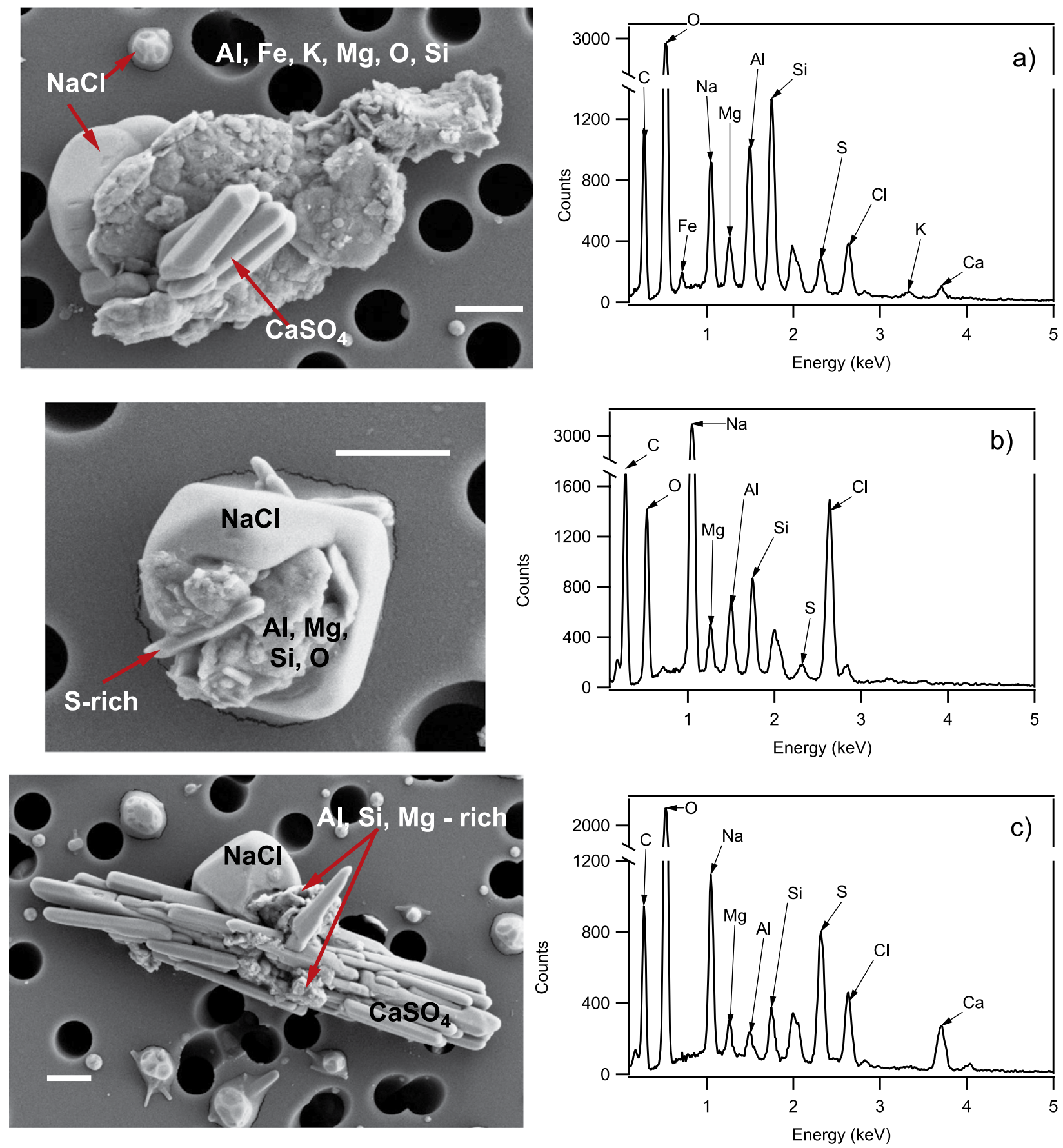

showed the air masses from the north, implying continuous sedimentation from the free troposphere into the Atlantic Ocean marine boundary layer and its ocean surface. We focused on areas where R/V Tara was at least $100 \mathrm{~km}$ from the coasts and back trajectories spent more than $24 \mathrm{~h}$ above the ocean.

The Aitken (0.01-0.1 $\mu \mathrm{m})$ and accumulation modes varied similarly in the western Pacific, the Atlantic, and the Caribbean, with geometric mean diameter (GMD) ranging from 0.04 to
* Scanning electron microscope (SEM) images of mineral dust particles collected west of Cuba. The corresponding X-ray spectra are shown on the right. The size bar is $1 \mu \mathrm{m}$.
$0.09 \mu \mathrm{m}$ in the Aitken mode and 0.14 to $0.22 \mu \mathrm{m}$ in the accumulation mode. On the other hand, there are more variations in the SSA mode in the Atlantic Ocean, with GMD varying from 0.18 to $0.51 \mu \mathrm{m}$. In the Pacific, the GMD mostly varied around 0.35 to $0.52 \mu \mathrm{m}$. The giant aerosol mode was only observed in the Atlantic and the Caribbean, with GMD values ranging between $1.0-1.9 \mu \mathrm{m}$ and $0.45-0.55 \mu \mathrm{m}$, respectively. This giant mode can be attributed to the dust sedimentation from the free troposphere. 

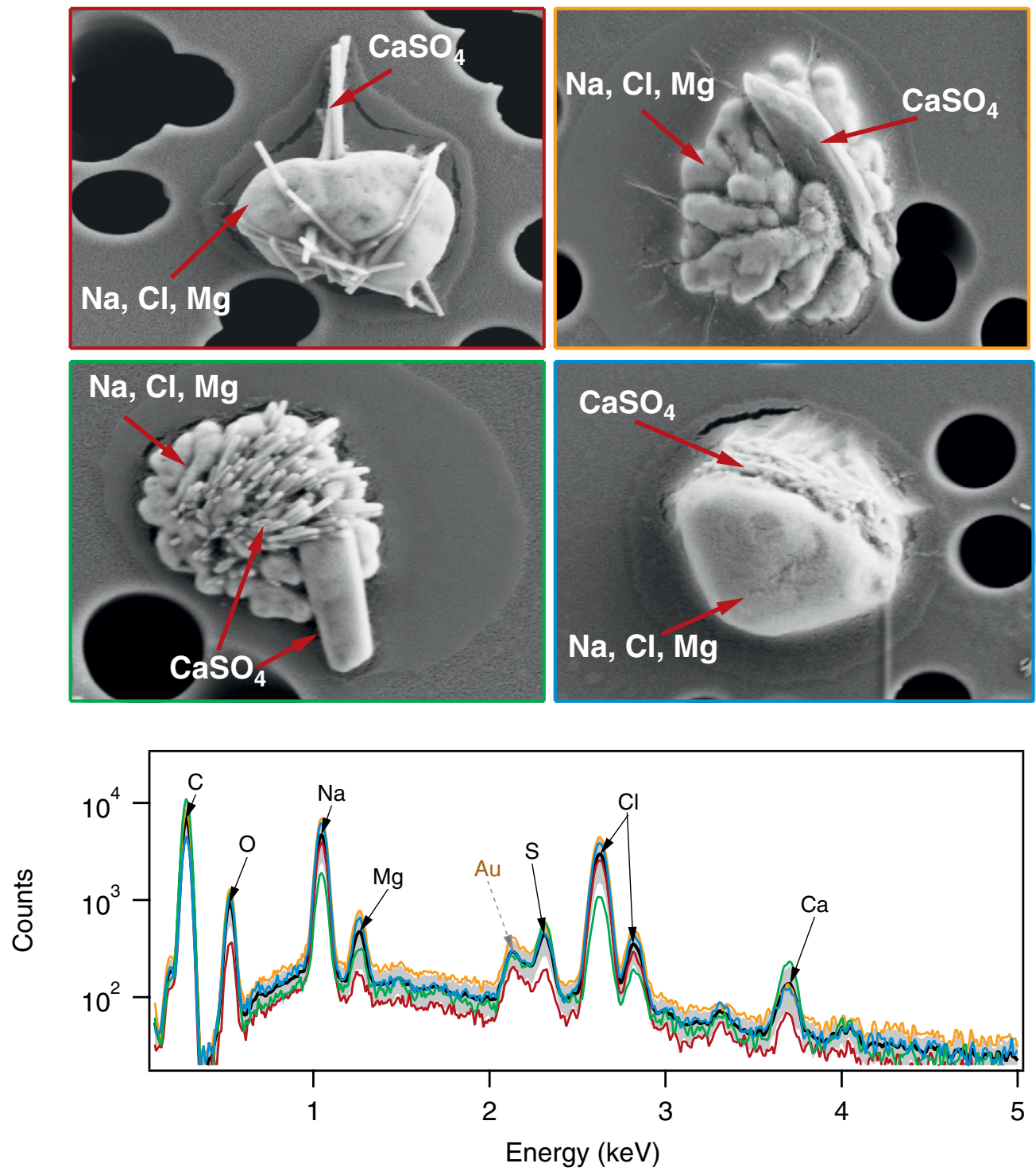

4 * SEM images of sea salt particles collected in the western Pacific Ocean. The four particles had similar X-ray spectra, shown below the images. The color of the frame of each SEM image corresponds to the color of the $X$-ray spectrum trace; the average of them is shown in black, with the standard deviation shown as a shaded gray area. The black holes are $0.8 \mu \mathrm{m}$ in diameter.
While the Tara was between $14^{\circ} \mathrm{N}$ and $1^{\circ} \mathrm{N}$, the Aitken mode dominated, with $55 \%-65 \%$ of the total number, but between the equator and $7^{\circ} \mathrm{S}$ the accumulation mode dominated with 50\%-53\%. The consistent marine air masses and persistent trade winds in the tropics allow the growth of Aitken mode particles to accumulation mode sizes. On the other hand, in most of the Atlantic transect, the Aitken mode had a larger number fraction, occasionally reaching 88\% (SSA fraction sometimes reached 18\%). Between $31^{\circ}$ and $26^{\circ} \mathrm{N}$, the Aitken and accumulation modes had similar number fractions around 50\%, and with the R/V Tara remaining around $26^{\circ} \mathrm{N}$ in the Atlantic, the Aitken-mode number fraction was consistently higher than the accumulation mode.

\section{Morphology and other properties} Identifying crystallization differences in sea salt aerosols' internal mixtures helps in obtaining improved refractive indices, shape, and size data for model calculations of the radiative forcing of dust and SSA. Additionally, the observation of internal or external mixtures helps determine which chemical reactions take place and how primary aerosol particles change during atmospheric transport. Sea salt particles dominate the particulate surface area in the marine atmosphere, making them the main light scatterer over the oceans, one of the dominant sources of aerosol mass, and an important component in the atmospheric cycles of $\mathrm{Cl}, \mathrm{S}$, and $\mathrm{N}$. Although sea salt particles were recently estimated to account for less 
than $30 \%$ of the total amount of marine CCN, they are good CCN and help determine the size distribution and number concentration of drops in marine clouds. Determination of the emitted sea salt's shape and internal mixing composition (e.g., its sulfate concentrations and sizes) aids the understanding of the radiative impact by constraining its optical properties and CCN contribution.

One of the main factors affecting SSA abundance and chemical composition is biological activity in the oceanic microlayer and mixed layer. Additionally, the chemical composition and size distribution of oceanic CCN are significantly affected by the abundance of organic matter in the seawater as well as the composition of the planktonic ecosystem. One of the major challenges is to understand which type of microorganisms, viruses, and bacteria are emitted from the marine environment; which remain viable after redeposition; which are transported from continental areas; and what impact they have on the marine environment. There are very few studies on the abundance of microbes in the atmosphere of the open ocean. Understanding what role oceans play as a source and sink of microorganisms (viruses and bacteria), and their atmospheric transport, can provide important insights on microbial diversity and the interplay between terrestrial and oceanic regions.

We collected more than 1,000 air filter samples, which will be analyzed for microbiome biodiversity and will enable us to correlate between the microbial and chemical composition of the SSA and open-ocean sea surface water.

\section{Outlook}

The information gained from the size distributions determined as part of the Tara Pacific Expedition will help us identify areas of interest that can be studied thoroughly for aerosol production mechanisms using satellite measurements, meteorological reanalyses, and other onboard oceanic measurements.

With electron microscopy and X-ray analysis, we will ascertain the size, shape, quantity, and elemental composition of all aerosols greater than $0.8 \mu \mathrm{m}$. Furthermore the biomass will be extracted from filters to assess for microbial diversity metagenomics, through genome sequencing. The pattern of microbial diversity and abundances will help lead to

\section{$\equiv$ METADATA}

BAMS: What would you like readers to learn from this article?

Michel Flores (Weizmann Institute of Science): We will be making available an extensive dataset of in situ measurements of the two boundary layers crossing the two oceans. From the evidence, we can see the terrestrial contribution to the marine aerosol downwind thousands of kilometers away from the continent. The rich and complicated surface ocean-lower atmosphere interactions we observed suggest that we still have a long way ahead to understand the internal structure and formation mechanisms of marine aerosols.

BAMS: What surprises you the most about observations from this voyage?

MF: From the crystallization differences in sea salt aerosols, we can indirectly see the strong link between marine biology and aerosols, all the way to clouds. Even with all the advancement we've done, there's still a big gap in our knowledge.

BAMS: What was the biggest challenge you encountered in this project?

MF: Making sure we collected high-quality data within exceptional circumstances of a 2.5-year expedition. We were invited to join the expedition just 3 months before it began, and we had to create a protocol that was simple, clear, and sustainable. We also had to quickly buy, build, install, and adapt to Tara's limited space, while minimizing the risk of malfunction since opportunities for repairs were limited. All scientists and crew members, if necessary, had to be able to follow our protocol. Without the amazing help from Tara's crew and Guillaume [Bourdin]'s hard work, we would not have been able to do it.

a comprehensive overview of the potential biological microbial exchange between the ocean and the atmosphere.

With additional measurements from future Tara missions, we expect to better understand feedbacks between marine ecology, mixed layer and microlayer properties, aerosols, and clouds, in different natural and anthropogenic environments. 